\title{
Las personas trans y el mecanismo de alternancia electoral a la luz de la OC-24/17
}

\author{
Jota Vargas Alvarado* \\ https://doi.org/10.35242/RDE_2020_30_9
}

Nota del Consejo Editorial

Recepción: 31 de mayo de 2020.

Revisión, corrección y aprobación: 6 de julio de 2020.

Resumen: El mecanismo de alternancia debe aplicarse con un enfoque convencional de derechos humanos, reconociendo plenamente la identidad de género de las personas trans, lo que conlleva utilizar su género autopercibido para optar por puestos en las nóminas de elección popular, así como órganos partidarios, delegaciones y actividades de capacitación, de acuerdo con la Opinión Consultiva número 24 de la Corte Interamericana de Derechos Humanos. Este enfoque no puede ser binario, ya que esta Opinión incluye a las personas no binarias dentro de la sombrilla trans, por lo que se debe reconocer su identidad de género, para no vulnerar derechos conexos como privacidad y participación política.

Palabras clave: Democracia / Derechos humanos / Derechos políticos / Derechos civiles y políticos / Igualdad de oportunidades / Población LGBTI / Derecho a la identidad / Derecho al sufragio / Participación política / Garantías electorales / Reforma política.

Abstract: The principle of parity and the alternation mechanism should be applied with a conventional focus of human rights fully acknowledging the gender identity of Trans people which leads to using their self-perceived gender to run for popular election posts according to Consultative Opinion 24 of the Inter-American Court of Human Rights. This focus cannot be binary since this Opinion excludes nonbinary people under the Trans umbrella. Thus, their gender identity must be acknowledged in order not to violate related rights such as privacy and political participation.

Key Words: Political parity / Political participation quotas /Gender equity / Gender identity / LGTBIQ population / Human Rights.

\footnotetext{
* Costarricense, abogada, correo jotavargascr@gmail.com. Licenciada en Derecho por la Universidad de Costa Rica. En la actualidad brinda asesoría jurídica en la Asociación Mulabi Espacio Latinoamericano de Sexualidades y Derechos. Ha llevado cursos de especialización en derechos humanos como Alfabetización Jurídica en Derechos Humanos de la Defensoría de las y los Habitantes e Incidencia Política Internacional de la Asociación Akahatá. Aprobó con distinción la tesis de grado titulada Derechos de las PersActivista LGBATIQ+, persona no binaria costarricense, en coautoría con Berioska Bejar Bascopé.
} 


\section{DERECHO ELECTORAL}

\section{INTRODUCCIÓN}

La garantía del derecho constitucional a la igualdad y a la no discriminación ha motivado cambios en el sistema electoral costarricense para fortalecer la participación política de las mujeres, pues nuestra normativa acoge que es un derecho humano reconocido en una sociedad democrática, representativa, participativa e inclusiva. Así, se evolucionó de un sistema de cuotas hacia la paridad con el Código Electoral de 2009.

Ese cuerpo legal, en su artículo segundo, establece que el principio de paridad implica que todas las delegaciones, nóminas y demás órganos pares estarán integrados por un $50 \%$ de mujeres y un $50 \%$ de hombres, y en las impares la diferencia no podrá ser superior a una. Para garantizar el cumplimiento de este principio, el mismo artículo establece el mecanismo de alternancia, entendido como el método por el cual dos personas del mismo "sexo" no puedan estar en forma consecutiva en la nómina de elección, sino que debe alternarse mujer-hombre u hombre-mujer.

Lo anterior responde a un mandato convencional de adoptar medidas afirmativas para la eliminación de la discriminación contra la mujer, a fin de buscar una igualdad real en los resultados. Así se puede apreciar, por ejemplo, en la Convención sobre la Eliminación de Todas las Formas de Discriminación Contra la Mujer (CEDAW por sus siglas en inglés), cuyo órgano de tratado, el Comité CEDAW, ha señalado que se deben tomar medidas que tiendan a eliminar la persistencia de estereotipos contra la mujer e incluye a las mujeres trans como mujeres, en las Observaciones Finales sobre el séptimo informe periódico a Costa Rica.

La Opinión Consultiva número 24 del 2017 de la Corte Interamericana de Derechos Humanos (OC-24/17) consagra el derecho a la igualdad y no discriminación de las personas LGBTI al asegurar que la noción de igualdad se desprende directamente de la unidad de naturaleza del género humano y es inseparable de la dignidad esencial de la persona, frente a la cual es incompatible toda situación que discrimine del goce de derechos. Añade que la orientación sexual y la identidad y expresión de género son categorías protegidas por la Convención Americana sobre Derechos Humanos (CADH).

De esta manera, este artículo pretende exponer en un primer momento definiciones relevantes sobre las poblaciones LGBATIQ, así como diferenciar sexo y género. Luego, desarrollar qué son las opiniones consultivas, los principales aportes de la OC-24/17 al tema bajo estudio y 


\section{DERECHO EIECTORAL}

referirse brevemente al control de convencionalidad. En una tercera fase se describe el mecanismo de alternancia en relación con la OC-24/17 y cómo ha resuelto el Tribunal Supremo de Elecciones (TSE), o alguno de sus órganos, casos relacionados con personas trans. Finaliza con una propuesta respecto a la participación política de personas no binarias y las personas intersex en nóminas, órganos y delegaciones, tanto plurinominales como uninominales, respetando el principio de paridad de género.

Así, no pretende este artículo centrarse en el principio de paridad, sino propiamente en el mecanismo de alternancia y su aplicación a las personas trans, no binarias e intersex. Tampoco se desea realizar un análisis constitucional en torno a sexo, género 0 al mecanismo de alternancia, pues sería objeto de otro artículo. Por último, no se busca desarrollar un estudio de datos y porcentajes de participación femenina en las elecciones nacionales o municipales, sino replicar los resultados de otras investigaciones al respecto.

\section{LGBATIQ: DEFINICIONES IMPORTANTES}

Las personas lesbianas, gays, bisexuales, asexuales, trans, intersex y queer (LGBATIQ) han sido históricamente discriminadas de muchas maneras en Costa Rica, América y el mundo entero, ya que no forman parte del constructo de lo que "tiene que ser" un hombre o una mujer y las relaciones afectivo-eróticas entre estas dos construcciones sociales. Cada una de estas poblaciones tiene necesidades propias que las diferencian de las otras. La orientación sexual (atracción) es distinta a la identidad de género (autopercepción) y ambas divergen del sexo, o los sexos, de una persona.

El sexo es una construcción social binaria que divide a las personas al nacer entre mujeres y hombres, de acuerdo con sus características biológicas, genéticas, hormonales, anatómicas y fisiológicas. El sexo asignado al nacer es definido a partir de la percepción que otras personas tienen sobre los genitales de la persona recién nacida. Sin embargo, las personas intersex no encajan dentro de esa división binaria del sexo, ya que poseen características que se les asignan social o científicamente a los dos sexos binarios. Así, se evidencia que el sexo no es una característica estática, sino que está basado en percepciones y constructos sociales (Corte IDH, 2017 y Thompson, 2019). 


\section{DERECHO ELECTORAL}

La identidad de género es la vivencia interna e individual de cada persona respecto a su género, es decir, su pertenencia a una categoría social que reúne a personas con características similares. En esta línea, una persona puede ser cisgénero si el género con el cual se identifica concuerda con el sexo asignado al nacer; transgénero si el género con el cual se identifica no es acorde al sexo que le fue asignado al nacer; agénero si la persona no se identifica con ningún género; o no binaria si su vivencia del género trasciende las construcciones sociales de mujer u hombre. Generalmente, se incluye a las personas agénero dentro de la sombrilla no binaria.

Por otro lado, la orientación sexual es la capacidad de cada persona de sentir una profunda atracción afectiva, emocional, física o sexual por otras personas de acuerdo con el género de estas últimas. Así, será heterosexual la persona que sienta atracción por personas del género opuesto dentro del binario; lesbiana, la mujer que sienta atracción por mujeres; gay, el hombre que sienta atracción por hombres; bisexual, la persona que sienta atracción por hombres y mujeres; asexual, la persona que no sienta atracción sexual por otras personas; o pansexual, la persona que sienta atracción por otras personas sin importar su sexo, identidad o expresión de género.

Asimismo, binarismo es la división de los sexos y los géneros en solo dos: mujer/hombre o femenino/masculino. La cisnormatividad es la asunción de que todas las personas "son" o "tienen que ser" cisgénero, lo que contribuye a la invisibilización de las identidades y vivencias trans y no binarias. Finalmente, la heteronormatividad es la suposición de que todas las personas "son" o "tienen que ser" heterosexuales, lo que conduce a la eliminación de las experiencias de otras orientaciones sexuales.

\section{3. ¿QUÉ DICE LA OC-24/17?}

Las opiniones consultivas son criterios de la Corte Interamericana de Derechos Humanos (Corte IDH), en respuesta a consultas de Estados parte u órganos de la Organización de Estados Americanos (OEA). Señala el artículo 64 de la Convención Americana sobre Derechos Humanos (CADH) que aquellos pueden consultar a la Corte IDH acerca de la interpretación de la $\mathrm{CADH}$ o de otros tratados concernientes a la protección de los derechos humanos ratificados por los Estados americanos, o acerca de la compatibilidad entre cualquiera de sus leyes internas y dichos instrumentos internacionales. 


\section{DERECHO EIECTORAL}

Por medio de las opiniones consultivas, la Corte IDH busca desentrañar el sentido, propósito y razón de las normas internacionales sobre derechos humanos para fortalecer este sistema de protección. De esta manera, los Estados deben incorporar la interpretación que emita la Corte IDH, ya que dentro de los deberes de los Estados se encuentra respetar los derechos y libertades reconocidos en la CADH y garantizar su libre y pleno ejercicio, según el artículo 2 de la CADH.

En el mismo sentido, en Costa Rica "las Opiniones Consultivas de la Corte Interamericana de Derechos Humanos tienen «pleno valor», ya que, como lo ha entendido la Sala Constitucional, tratándose de Derechos Humanos lo indicado en estas vinculan al Estado costarricense" (Thompson, Bejar y Vargas, 2019, p. 176) y que la Corte IDH "es el órgano natural para emitir criterios sobre la Convención, la fuerza de interpretaciones y enjuiciamiento de normas nacionales, aunque sea en una mera consulta; tendrá, entonces, el mismo valor de la norma que interpreta" (Thompson, Bejar y Vargas, 2019, p. 177).

La OC-24/17 representa un avance en la protección y la garantía de los derechos humanos de las personas LGBATIQ en los Estados miembros del continente. Esta Opinión responde a una consulta realizada por Costa Rica sobre el derecho al nombre de las personas trans y el reconocimiento de los derechos patrimoniales derivados de parejas de personas del mismo sexo.

Al responder esto, la Corte IDH señala que el cambio de nombre y la adecuación de los registros públicos y de los documentos de identidad para que estos sean conformes a la identidad de género autopercibida constituye un derecho protegido por la CADH, por lo que los Estados están en la obligación de reconocer, regular y establecer los procedimientos adecuados para tales fines; que dicho procedimiento debe ser administrativo o notarial, integral, basado únicamente en el consentimiento libre e informado de la persona solicitante, confidencial, expedito, que tienda a la gratuidad y que no requiera la acreditación de operaciones quirúrgicas u hormonales ${ }^{1}$.

${ }^{1}$ Corte IDH (2017, párrs. 105-114, 117-161 y 229). Sobre las implicaciones de cada requisito, véase OEA (2020) y Synergía (2020). 


\section{DERECHO ELECTORAL}

Lo anterior, señala la Corte IDH, debe abarcar la rectificación de la anotación del género o las menciones del sexo y la adecuación de su imagen, para que sean conformes con su identidad de género autopercibida. El reconocimiento pleno de la identidad de género por parte de los Estados resulta de vital importancia para garantizar el pleno goce de los derechos humanos de las personas trans, sin que el sexo registral deba estar sujeto a su "genitalidad".

Más específicamente, sobre el sexo registral y la obligación de los Estados de crear procedimientos para que las personas trans puedan modificar el componente o la mención al sexo, la Corte IDH señaló que:

...el sexo, así como las identidades, las funciones y los atributos construidos socialmente que se atribuye a las diferencias biológicas en torno al sexo asignado al nacer, lejos de constituirse en componentes objetivos e inmutables del estado civil que individualiza a la persona, por ser un hecho de la naturaleza física o biológica, terminan siendo rasgos que dependen de la apreciación subjetiva de quien lo detenta y descansan en una construcción de la identidad de género autopercibida relacionada con el libre desarrollo de la personalidad, la autodeterminación sexual y el derecho a la vida privada. Por ende, quien decide asumirla, es titular de intereses jurídicamente protegidos, que bajo ningún punto de vista pueden ser objeto de restricciones por el simple hecho de que el conglomerado social no comparte específicos y singulares estilos de vida, a raíz de miedos, estereotipos, prejuicios sociales y morales carentes de fundamentos razonables. Es así que, ante los factores que definen la identidad sexual y de género de una persona, se presenta en la realidad una prelación del factor subjetivo sobre sus caracteres físicos o morfológicos (factor objetivo). En ese sentido, partiendo de la compleja naturaleza humana que lleva a cada persona a desarrollar su propia personalidad con base en la visión particular que respecto de sí mismo tenga, debe darse un carácter preeminente al sexo psicosocial frente al morfológico, a fin de respetar plenamente los derechos de identidad sexual y de género, al ser aspectos que, en mayor medida, definen tanto la visión que la persona tiene frente a sí misma como su proyección ante la sociedad. (Corte IDH, 2017, párr. 95). 


\section{DERECHO EIECTORAL}

Añade la Corte IDH que la $\mathrm{CADH}$, en virtud de los derechos a la protección de la vida privada y a la protección de la familia, protege el vínculo familiar que puede resultar de la relación de una pareja del mismo sexo; por lo que los Estados deben reconocer y garantizar todos los derechos que se derivan de un vínculo familiar entre personas del mismo sexo, sin discriminación con respecto a las que están constituidas por parejas heterosexuales; de forma que garanticen el acceso a todas las figuras ya existentes en los ordenamientos jurídicos internos, incluido el derecho al matrimonio.

De este modo, las personas trans tienen derecho al respeto $y$ al reconocimiento de su identidad de género autopercibida; por lo que los Estados deben garantizar procedimientos para la rectificación del género o sexo registral en los documentos de identidad, actas de nacimiento y demás registros. Si bien el Estado de Costa Rica, a través del Registro Civil del Tribunal Supremo de Elecciones, habilitó un procedimiento para el cambio de nombre de las personas trans mayores de edad el cual cumple con todos los requisitos formales establecidos en la OC-24/17; no alineó dicho proceso para que las personas trans pudieran realizar la rectificación de su género o sexo registral, sino que se limitó a eliminar este dato de los documentos de identidad públicos; tampoco incluyó a las personas menores de edad (TSE, Acta 49-2018, art. 1).

En este aspecto, es menester recalcar que la Corte IDH fue clara al señalar que las personas trans tienen derecho a modificar el componente de género conforme a su identidad, en los casos en que los países registren el género. Por su parte, indicó dicho tribunal interamericano que en los casos de los Estados que registran el sexo asignado al nacer, estos deben adecuar procedimientos para que las personas trans puedan modificar ese dato (sexo registral), a fin de que corresponda con su identidad de género. Es por ello que, tanto en la OC-24/17 como en este artículo, se hace referencia a este derecho como la modificación del componente del "género o sexo", ya que depende del sistema registral de cada país. Además, que los derechos a la imagen, cambio de nombre y rectificación del componente sexo son derechos que deben garantizarse a las personas trans menores de edad. 


\section{DERECHO ELECTORAL}

\section{Control de Convencionalidad}

El control de convencionalidad es el análisis y la aplicación de los estándares internacionales de derechos humanos que realiza una persona o institución operadora jurídica como lo es el Tribunal Supremo de Elecciones (TSE), en su actuar y en sus distintas resoluciones. Al respecto, el TSE ha señalado que:

...efectivamente, tal y como lo asevera el recurrente, se encuentra obligado a ejercer -y ciertamente así lo hace- un control no solo de constitucionalidad sino también de convencionalidad de las actuaciones efectuadas por las diversas autoridades públicas y los partidos políticos que pudieran afectar los derechos fundamentales de carácter político electoral de los ciudadanos. Esa potestad para efectuar tal control de convencionalidad, de carácter exclusivo y excluyente en materia electoral, por mandato del constituyente originario, reside en el hecho de que este, como máxima autoridad en la materia electoral, es el órgano naturalmente llamado a defender los derechos fundamentales de este tipo, utilizando como parámetro normativo no solo la Constitución Política y los principios que la informan, sino además los instrumentos del Derecho Internacional de los Derechos Humanos suscritos y ratificados por el país; ejercicio que, en sí mismo, implica tal control de convencionalidad. (Resolución 1337-E1-2015).

\section{Mecanismo de Alternancia}

En Costa Rica, el Código Electoral contempla el mecanismo de alternancia como un medio efectivo de garantizar el principio de paridad de género en elecciones para cargos plurinominales y uninominales, órganos partidarios y actividades de capacitación. El principio de paridad se refiere a la cantidad de mujeres en las nóminas partidarias; en cambio, el mecanismo de alternancia o posición de mandato se refiere a la ubicación de las mujeres en las nóminas partidarias, en donde se debe turnar a las personas por su género (sostiene esta autoría) de forma alternada mujerhombre-mujer o a la inversa. Lo anterior no solo busca una igualdad formal, sino que apunta hacia una igualdad real (de participación y resultado) entre los géneros, ya que es un sistema de "cuota neutral", en donde las mujeres pueden optar por puestos elegibles. 


\section{DERECHO EIECTORAL}

El mecanismo de alternancia responde a la incorporación de la diversidad de género en la democracia, en igualdad de condiciones, por lo que deriva del derecho a la participación política, la libertad y la igualdad. Asimismo, debe ser aplicado en papeletas presidenciales y diputadiles; en papeletas de alcaldías, sindicaturas e intendencias; así como en las delegaciones, órganos internos y actividades de capacitación de los partidos políticos. Este mecanismo electoral se ha extendido a elecciones universitarias. Cabe destacar que este mecanismo bajo ninguna circunstancia puede ir en contra de mandatos constitucionales como la igualdad, no discriminación o el derecho a la privacidad (o intimidad según el numeral 24 de la Constitución Política).

Tanto el Código Electoral en los artículos 2, 52.ñ, 52.p, 53 y 103 como la Constitución Política en el artículo 95.8 explican los principios democráticos, el principio de paridad y el derecho de no discriminación haciendo referencia al "género" de las personas. Asimismo, el transitorio II del Código Electoral se refiere a "los principios de paridad y alternancia de género". También, artículos académicos han explicado la libre determinación partidaria para decidir el género que encabeza las nóminas o listas mencionando el "género" (Picado, 2014).

Por lo anterior, haciendo una lectura integral de la normativa nacional con enfoque en derechos humanos a la luz de estándares convencionales, se debería entender que cuando la norma explica el mecanismo de alternancia se refiere al género de las personas; que, al mencionar el sexo, no se refiere al sexo asignado al nacer, sino al dato comprobable del sexo registral que debe poder modificarse en relación con la identidad de género de las personas. Por lo que, en este artículo, al explicar el mecanismo de alternancia, se hace referencia al género.

El multipartidismo y la no obligación de los partidos políticos de alternar el género en las cabeceras de las nóminas generaron un resultado no deseado por los esfuerzos para garantizar la paridad de mujeres y hombres en órganos de representación, en específico en la Asamblea Legislativa; ya que la representación de mujeres en este órgano en el 2014 fue menor que la del 2010. En vista de lo anterior, la Sala Constitucional y el Tribunal Supremo de Elecciones reinterpretaron el principio de paridad y decidieron incorporar no solo la paridad vertical, sino la paridad horizontal en las nóminas de elección popular. Así, las cabeceras de las siete listas, que representan cada provincia, deben contar con al menos tres mujeres. Esta interpretación generó una 


\section{DERECHO EIECTORAL}

representación de $45 \%$ de mujeres en la Asamblea Legislativa en las elecciones del $2018^{2}$.

\section{6. ¿Qué SuCEDE CON LAS PERSONAS TRANS EN APLICACIÓn del MeCANismo DE Alternancia?}

El TSE ha manifestado que el género no es un dato registrable y que la rectificación del nombre no implica un cambio de sexo registral, que el sexo asignado al nacer continuará en las bases de datos del Registro Civil sin modificarlo, aludiendo relevancia en el ámbito médico ${ }^{3}$. En el 2018 un partido político provincial presentó en los primeros tres lugares de la nómina de diputaciones a una mujer cisgénero, una mujer trans y una mujer cisgénero, ya que la Dirección General del Registro Electoral de este Tribunal no permitió que la mujer trans ocupara un escaño de mujer. En el 2020 el TSE rechazó la postulación de un concejal suplente (hombre cisgénero), ya que la postulación superior en la lista era asumida por una mujer trans $y$, según este Tribunal, no cumplía con el mecanismo de alternancia ${ }^{4}$.

De esta manera, el TSE no reconoce la identidad de género de las personas trans de forma integral e incumple la OC-24/17 de la Corte IDH, ya que contempla únicamente el sexo asignado al nacer de las personas y no su género, valiéndose de que, pese a que se le denomina "principio de paridad de género", el Código Electoral en su artículo 2 expresamente se refiere al sexo cuando describe el mecanismo de alternancia. En este

\footnotetext{
${ }^{2}$ Mediante resolución n. ${ }^{\circ}$ 1724-E8-2019 del 27 de febrero del 2019, el Tribunal Supremo de Elecciones señaló que la implementación del criterio de paridad horizontal será aplicable al proceso de inscripción de candidaturas correspondiente a las elecciones municipales hasta el 2024. Es por ello que, en este artículo, no se analiza la implementación del principio de paridad horizontal en las elecciones municipales. Tampoco es objeto de estudio de este texto analizar la jurisprudencia constitucional y electoral, pero se insta a las personas lectoras interesadas a desarrollar el tema en una investigación con ese propósito. Al respecto, se puede tomar como base el listado del pie de página número 1.

${ }^{3}$ En este artículo se han mencionado la orientación sexual y el derecho al matrimonio entre personas del mismo sexo, en primer lugar, para diferenciarlo de la identidad de género y el derecho al reconocimiento de la identidad de género; pero, también, porque el TSE había manifestado su oposición al cambio de sexo registral en la Consulta Legislativa sobre la Ley de Identidad de Género en el 2016, con base en que esto iba a permitir, de forma indirecta, el matrimonio igualitario. Posterior al 26 de mayo de 2020 con las inscripciones de varios matrimonios entre personas del mismo sexo, no queda clara cuál es la objeción del TSE a realizar el cambio del sexo registral por motivo de identidad de género, más allá de la sostenida "relevancia médica".

${ }^{4}$ Para ampliar sobre este tema, véase TSE, acta 49-2018, (párrs. 20-21 y 54), TSE, resolución 8764-E3-2019 y Alvarado (2017).
} 


\section{DERECHO EIECTORAL}

sentido, cobra importancia aclarar que tanto este Código como otras leyes usan indiferenciadamente los conceptos de sexo y género ${ }^{5}$.

Además, al igual que la Corte IDH, la propia Sala Constitucional ha señalado que el género es parte del concepto de sexo. En la Sentencia 7128-2007, esta Sala indicó que el derecho no puede mantenerse ajeno al reconocimiento del derecho a la identidad sexual, ya que forma parte del derecho a la identidad de la persona y es inherente a ella. Agrega el tribunal constitucional que el sexo es una realidad múltiple configurada por el componente genético o "cromosomático", el componente morfológico y el componente psicosocial, este último explicado como "el género: masculino o femenino" (Sala Constitucional, Sentencia 71282007, Considerando 3).

Señala la Sala Constitucional que el derecho "debe prever, mediante disposiciones, aquellos casos", refiriéndose a las personas trans, "en los que ciertos individuos no han seguido la línea pronosticada en la evolución de su identidad sexual y a pesar de que tienen un sexo, quieren pertenecer al otro". De modo que esta Sala admite la posibilidad de que el elemento psicológico permita la determinación del sexo de una persona (Sala Constitucional, Sentencia 7128-2007, Considerando 3) ${ }^{6}$.

En esta línea, la Corte IDH, en la OC-24/17, señaló que la falta de reconocimiento de la identidad de género o sexual podría resultar en una censura indirecta a las expresiones que se aparten de los estándares cisnormativos o heteronormativos, como si estas personas no contaran con la protección legal y el reconocimiento de sus derechos en igualdad de condiciones; este reconocimiento es necesario para garantizar el ejercicio de todos los derechos vitales en una sociedad democrática, incluidos los políticos y, por ende, electorales.

\footnotetext{
${ }^{5}$ Para ampliar sobre el binarismo dentro de la legislación nacional y la confusión entre género y sexo de quien legisla, véase Thompson, Bejar y Vargas, 2019, pp. 55, 74-79.

6 Para una lectura más completa sobre lo que han señalado el Tribunal Supremo de Elecciones y la Sala Constitucional respecto a este tema, se sugiere revisar los votos 1863-1999, 2837-E-1999, 1536-E-2001, 405E8-2008, 3399-E8-2009, 3671-E8-2010, 4303-E8-2010, 4391-E8-2010, 5133-E1-2010, 6165-E8-2010, 0784E8-2011, 1677-E8-2012, 3782-E1-2013, 3603-E8-2016, 1724-E8-2019 y 8764-E3-2019, del Tribunal Supremo de Elecciones; y las resoluciones 2313-1995, 3419-2001, 2771-2003, 13118-2010, 1966-2012, 4630-2014, 1217-2015, 8750-2015, 16070-2015, 14525-2017, 20061-2017, 2941-2018, 3423-2018, 13502-2018, 163862018, 16787-2018, 18431-2018, 3333-2019, 3478-2019, 3481-2019, 3486-2019, 6292-2019, 8181-2019, 9203-2019, 9750-2019, 10199-2019, 10683-2019, 10702-2019, 11197-2019, 11198-2019, 11193-2019, 11194-2019, 11195-2019, 11199-2019, 11200-2019, 11201-2019, 15177-2019, 16615-2019, 16616-2019, 22973-2019, 24514-2019, 34780-2019 y 91921-2019, de la Sala Constitucional.
} 


\section{DERECHO EIECTORAL}

Por lo que, al hacer un control de convencionalidad, el TSE debe respetar la identidad de género autopercibida de las personas trans $y$, de esta manera, garantizar que ocupen un puesto, plaza o escaño conforme a su género. Es decir, una mujer trans debe optar por un escaño de una mujer (entre dos hombres) y un hombre trans por uno de un hombre (entre dos mujeres). Esto responde a que el derecho a la identidad de género tiene como base el derecho a la privacidad, principio de libre desarrollo de la personalidad, derecho a la igualdad, derecho a la no discriminación, derecho a la dignidad humana, derecho a la libertad, principio de autonomía $y$, en este caso en particular, el no reconocimiento de la identidad de género por parte del Estado vulneraría, además, los derechos de toda persona a la participación política activa, a ser elegida y ejercer puestos públicos, conforme a los artículos $1.1,24$ y 27 de la $\mathrm{CADH}^{7}$.

La Sala Constitucional se ha referido al derecho a la intimidad de las personas trans en la resolución número 16787-2018 del 5 de octubre del 2018, al obligar al TSE a que sea suprimida de la consulta pública en el sitio web del Tribunal Supremo de Elecciones la información relacionada con el sexo registrado de una persona al nacer. Para ello, esta Sala reiteró el criterio del TSE de que, en cumplimiento del derecho a la intimidad, debe eliminarse toda trazabilidad que pudiere resultar estigmatizante para un ser humano como lo es la publicación del sexo asignado al nacer.

Pretender que las mujeres trans y los hombres trans participen en nóminas, delegaciones u órganos de acuerdo con el sexo que les fue asignado al nacer violenta el derecho a la intimidad, ya que se hace público este dato que tanto el TSE como la Sala Constitucional han buscado resguardar $y$, además, es notorio que aquella persona que esté entre dos personas de su mismo género es una persona trans. Es por ello, que no se puede analizar un derecho humano o un mecanismo electoral de forma ajena a los demás derechos humanos y principios constitucionales en un Estado democrático de derecho.

Hasta que el TSE no realice un control de convencionalidad, una reforma o un nuevo decreto para garantizar plenamente el derecho a la identidad de género de las personas trans, se debería considerar el género autopercibido de cada persona para la aplicación del principio de paridad y

\footnotetext{
7 Sobre el control de convencionalidad véase TSE, acta 49-2018, (considerandos I-V), Corte IDH (2017, párrs.
} 26,171 y 229), Soto (2017, p. 153) y Miranda (2015, p. 65). 


\section{DERECHO EIECTORAL}

el mecanismo de alternancia. Este dato se puede corroborar de la manera que se constatan otros requisitos no registrables o por medio de la anotación marginal del cambio de nombre por identidad de género, a la que solo debería tener acceso el TSE, tal y como sugirió el magistrado Brenes Villalobos en el voto salvado de la resolución 8764-E3-2019.

\section{7. ¿Y QUÉ SUCEDE CON LAS PERSONAS NO BINARIAS?}

La OC-24/17 incluye dentro del término trans a las personas no binarias (PNB), por lo que están cobijadas por los derechos a la identidad de género autopercibida, su reconocimiento por parte de los Estados y al derecho a la privacidad o intimidad, desarrollados en apartados anteriores. De esta manera, debería respetarse su género autopercibido. Sin embargo, el Código Electoral (artículo 2), además de confundir los términos género y sexo, está cargado de binarismo, ya que el principio de paridad y el mecanismo de alternancia están explicados expresamente como la participación política entre "hombres y mujeres". Por lo tanto, es necesario una aplicación de control de convencionalidad por parte del TSE, un cambio legislativo o una interpretación constitucional, para así explicar lo que sucedería cuando una PNB desee enlistar una nómina ${ }^{8}$.

En las elecciones para cargos plurinominales, así como en los órganos de los partidos, si la PNB encabeza la lista, el siguiente lugar podría ser ocupado por una persona de cualquier género. Si no encabeza la lista hay dos posibles soluciones. La primera sería que la PNB ocupe el puesto del género que continuaría la alternancia, de la siguiente forma:

\footnotetext{
8 El TSE señaló en el voto 8763-E3-2019 que le corresponde al legislador incorporar variables como los derechos de personas intersex y prever escenarios en los que deseen postularse personas queer (no binarias), justificándose en que, con base en la redacción actual del Código Electoral, no sería posible determinar qué sexo correspondería al segundo lugar de una nómina cuyo encabezamiento fuera una persona intersex. También, al respecto, vale la pena recordar la resolución 3435-1992 de la Sala Constitucional, la cual indicó que en aras de evitar desigualdades y discriminaciones futuras que pudieran surgir al aplicarse la carta fundamental y otros instrumentos jurídicos vigentes, cuando en la legislación se utilicen los términos "hombre" o "mujer", deberán entenderse como sinónimos del vocablo "persona", y con ello eliminar toda posible discriminación "legal" por razón de género.
} 


\section{DERECHO ELECTORAL}

Caso 1.1

$\rightarrow$ Mujer

$\rightarrow$ PNB

$\rightarrow$ Mujer

$\rightarrow$ Hombre

$\rightarrow$ Mujer
Caso 1.2

$\rightarrow$ Hombre

$\rightarrow$ PNB

$\rightarrow$ Hombre

$\rightarrow$ Mujer

$\rightarrow$ Hombre

Como se evidencia en el caso 1.2 , en una nómina u órgano de cinco plazas podría suceder que la representación de las mujeres sea de $20 \%$; lo que sería contrario al espíritu de la norma.

La segunda solución sería que la PNB no interfiera en la alternancia, por lo que la siguiente persona debería corresponder al género binario opuesto al de la plaza anterior a la PNB; de la siguiente forma:

\section{Caso 2.1}

$\rightarrow$ Mujer

$\rightarrow$ PNB

$\rightarrow$ Hombre

$\rightarrow$ Mujer

$\rightarrow$ Hombre

\section{Caso 2.2}

$\rightarrow$ Hombre

$\rightarrow$ PNB

$\rightarrow$ Mujer

$\rightarrow$ Hombre

$\rightarrow$ Mujer

En ambos casos, en una nómina u órgano de cinco nominaciones, la participación de las mujeres y de los hombres es de $40 \%$ por igual, acorde al espíritu de la norma, asimismo en todas las nóminas u órganos impares la participación de mujeres y de hombres será igual (si solo participa una PNB). Además, la diferencia entre la cantidad de hombres y mujeres en nóminas u órganos pares nunca será mayor a una. Por lo tanto, la 


\section{DERECHO ELECTORAL}

solución que más se adecúa al respeto por la identidad de las personas no binarias, sin violentar derechos que han adquirido las mujeres, sería esta última. En caso de que la PNB encabece la lista, el género de la segunda persona podrá ser mujer u hombre y continuar la alternancia, tanto vertical como horizontal, como se señaló.

En las elecciones para cargos uninominales, se recomienda que para:

- Papeleta presidencial: el cargo de presidencia y de quien encabeza la lista de vicepresidencias corresponda a cualquier género (mujer, hombre o PNB). Si la primera vicepresidencia corresponde a una PNB, se recomienda que la segunda vicepresidencia sea ocupada por una persona del género binario opuesto a quien ocupe la presidencia; en el caso de que la primera vicepresidencia corresponda a una mujer o a un hombre, la segunda vicepresidencia puede ser asumida por una persona del género binario opuesto al encabezamiento o por una PNB.

- Papeleta de alcaldía: al puesto de alcaldía pueda postularse una persona de cualquier género; si es una PNB, la primera vicealcaldía pueda ser ocupada por una persona de cualquier género binario. Si el puesto de alcaldía es ocupado por un género binario, la primera vicealcaldía pueda ser ocupada por el género binario opuesto o por una PNB; si es ocupado por una PNB, se recomienda que la segunda vicealcaldía sea asumida por una persona del género binario opuesto al de la alcaldía.

- Papeleta sindical: esta nómina pueda ser encabezada por cualquier género y que la candidatura a suplencia deba ocuparla el género binario opuesto o una PNB; si la nómina la encabeza una PNB, que la suplencia pueda ser ocupada por una persona de cualquier género binario.

- Papeleta de intendencia: pueda ser encabezada por cualquier género; la candidatura a viceintendencia corresponda a una persona del género binario opuesto o por una PNB; si la intendencia la ocupa una PNB, la viceintendencia pueda ser asumida por una persona de cualquier género binario.

Por otro lado, en un caso donde se seleccione a las personas por número de votos individuales recibidos, como sucede en ciertos mecanismos electorales universitarios, se recomienda que se seleccione primero a la 


\section{DERECHO EIECTORAL}

persona con más votos; si es una PNB, que se seleccione a la segunda persona con más votos para ocupar la segunda nómina (sin distinción por género) y se continúe con la alternancia. En caso de que la persona con más votos sea mujer u hombre, se recomienda que se continúe con la alternancia hasta que la PNB supere en votos a una persona y se continúe la alternancia como en los casos 2.1 y 2.2 explicados.

\section{Personas intersex y el mecanismo de alternancia}

Finalmente, el TSE, en la resolución 8764-E3-2019, mostró su preocupación por las personas intersex. Al respecto, cabe indicar que la posición de esta autoría es que las personas intersex puedan tener igual acceso al cambio de nombre y modificación de la anotación del sexo registral que las personas trans, si así lo desean y si este no corresponde con su identidad de género autopercibida. De esta forma, podrían acceder a los derechos políticos descritos de la misma manera como lo harían las personas cisgénero, en caso de que no cambien su sexo registral; o como lo harían las personas trans, en caso de que sí lo modifiquen. De aparecer un sexo indeterminado en su acta de nacimiento, la persona intersex podría optar por el mecanismo propuesto en el apartado de las personas no binarias.

\section{Reflexiones finales}

El derecho no puede ser un ente estático u obsoleto, por lo que las personas operadoras del derecho deben actualizarlo continuamente, de acuerdo con los cambios sociales y con la realidad social. Los derechos electorales, en especial el principio de paridad y el mecanismo de alternancia, deben ser analizados bajo el lente de los derechos a la igualdad y a la no discriminación, a la identidad de género y a la privacidad o intimidad.

EI TSE no debería sostener una postura contraria a los estándares internacionales de derechos humanos, sino que debe ejercer un control de convencionalidad $y$ hacer uso de sus atribuciones constitucionales y legales para garantizar vía reforma o decreto la participación política activa de las personas trans, incluidas las personas no binarias. No sería la primera vez que el TSE, con la finalidad de garantizar la participación política de las personas, interprete de forma amplia una norma. 


\section{DERECHO EIECTORAL}

Considera esta autoría que es inhumano y violatorio de los derechos humanos que las personas trans deban escoger entre el derecho al sufragio activo y el derecho a su privacidad o su intimidad. Así como se ha garantizado el cambio de nombre, está en manos del TSE una reforma para garantizar vía ocurso la modificación del componente sexo, para que este corresponda con el género autopercibido por cada persona.

En la misma línea, el mecanismo de alternancia no puede ser explicado ajeno al contexto, al principio de paridad de género, la normativa electoral, la Constitución Política y los tratados internacionales y sus respectivas interpretaciones. Por lo que, cuando la norma se refiere al "sexo", se debe entender como "género", en cumplimiento de lo establecido por la OC-24/17.

Finalmente, hasta que el TSE no garantice plenamente el derecho a la identidad de género de las personas trans, se debería corroborar el género, para la aplicación del principio de paridad y el mecanismo de alternancia, de la manera que se constatan otros requisitos no registrables o por medio de la anotación marginal del cambio de nombre por identidad de género, a la que solo debería tener acceso el TSE. De esta manera se garantizaría tanto el derecho a la privacidad e intimidad como los derechos políticos $y$, en específico, electorales de todas las personas trans.

\section{Referencias bibliográficas}

Artavia, P. y otras. (2018). Guía sobre la Opinión Consultiva OC-24/2017 la Corte IDH: sobre identidad de género, igualdad y no discriminación a parejas del mismo sexo y sus implicaciones jurídicas. San José: ACCEDER y FDI.

Benavides, T. (2019). El efecto de los mecanismos de paridad vertical y horizontal en la representación política en Costa Rica: el caso de las elecciones legislativas de 2018. Revista de Derecho Electoral, (27), 151183.

Chinchilla, H. y otras. (2018). LGBTIQ de la A a la Z. San José: FDI.

Chinchilla, H. y otras. (2018). ¿Qué derechos tengo? Guía para el reconocimiento de derechos a la identidad de género y relación de parejas del mismo sexo. San José: FDI. 


\section{DERECHO EIECTORAL}

Chinchilla, H. y otras. (2018). Derechos básicos y fundamentales. San José: FDI.

Comisión Interamericana de Derechos Humanos. (2015). Violencia contra Personas Lesbianas, Gays, Bisexuales, Trans e Intersex en América. Washington D. C.: OEA.

Comisión Internacional de Juristas. (2016). Principios de Yogyakarta, principios sobre la aplicación de la legislación internacional de derechos humanos en relación con la orientación sexual y la identidad de género. Yogyakarta. Recuperado de https://yogyakartaprinciples.org/principles-sp/

Costa Rica. Asamblea Constituyente. (1949). Constitución Política de la República de Costa Rica y todas sus reformas. San José: Asamblea Constituyente.

Costa Rica. Asamblea Legislativa. (2009). Código Electoral. Ley n. 8765 y todas sus reformas. San José: Poder Legislativo.

Costa Rica. Tribunal Supremo de Elecciones. (2018). Reforma al Reglamento del Registro del Estado Civil y Reglamento de la cédula de identidad con nuevas características. Decreto n. ${ }^{\circ}$ 07-2018. San José: TSE.

Flores, A. L. (2018). El Registro Civil soporte del derecho a la identidad. Las personas trans y el reconocimiento de la identidad de género. Revista de Derecho Electoral, (25), 215-231.

Matarrita, M. A. y Zamora, E. M. (2015). Paridad de género y capacitación partidaria en Costa Rica. Revista de Derecho Electoral, (19), 90-129.

Miranda, H. (2015). Derechos Fundamentales en América Latina. San José: Editorial Jurídica Continental.

Picado, H. y Brenes, L. D. (2014). Evaluando la paridad y alternancia. Revista de Derecho Electoral, (18), 384-414.

Organización de los Estados Americanos. (1969). Convención Americana sobre Derechos Humanos. México: OEA.

Organización de los Estados Americanos. (2020). Panorama del reconocimiento legal de la identidad de género en las Américas. Recuperado de: http://clarciev.com/identidaddegenero/public/files/PANORAMA\%20DEL\%20 RECONOCIMIENTO\%20LEGAL\%20DE\%20LA\%20IDENTIDAD\%20DE\%20GE NERO\%20EN\%20LAS\%20AMERICAS.pdf

Organización de las Naciones Unidas. (1979). Convención sobre la eliminación de todas las formas de discriminación contra la mujer. New York: ONU. 


\section{DERECHO EIECTORAL}

Soto, L. (2017). Alcances en materia jurídico electoral de la recién promulgada Ley 9379 para la Promoción de la Autonomía Personal de las Personas con Discapacidad: Un análisis de la función cuasilegislativa del Tribunal Supremo de Elecciones. Revista de Derecho Electoral, (24), 153-174.

Synergía. (2020). Lineamientos para la implementación de la Opinión Consultiva n. ${ }^{\circ} 24$ en el marco del reconocimiento legal de la identidad de género. Recuperado de: http://clarciev.com/identidaddegenero/public/files/SYNERGIA\%20$\% 200 C 24 . p d f$

Thompson, J., Bejar, B. y Vargas, J. (2019). Derechos de las personas intersex en Costa Rica a la luz de los estándares de derechos humanos (tesis de licenciatura). Universidad de Costa Rica, San José, Costa Rica.

Zamora, E. M. (2009). Los derechos políticos de la mujer: 1986-2006. Revista de Derecho Electoral, (7), 1-44.

Zamora, E. M. (2010). El principio de paridad de género en el nuevo Código Electoral. Revista de Derecho Electoral, (9), 1-26.

Zamora, E. M. (2014). El mecanismo de alternancia en el nuevo Código Electoral y su aplicación. Revista de Derecho Electoral, (17), 270-303.

\section{JURISPRUDENCIA}

Comité para la Eliminación de la Discriminación contra la Mujer de las Naciones Unidas. (2017). Observaciones finales sobre el sétimo informe periódico a Costa Rica. CEDAW/C/CRI/CO/7 del veintiuno de julio.

Corte Interamericana de Derechos Humanos. (2017). Opinión Consultiva OC24/17 del veinticuatro de noviembre.

Corte Interamericana de Derechos Humanos. (2012). Caso Atala Riffo y Niñas vs. Chile, Fondo, Reparaciones y Costas, Sentencia del 24 de febrero, Serie C n. ${ }^{\circ} 239$.

Sala Constitucional, Poder Judicial de la República de Costa Rica. (2007). Resolución 7128-2007 de las dieciséis horas con treinta y ocho minutos del veintitrés de mayo.

Sala Constitucional, Poder Judicial de la República de Costa Rica. (2018). Resolución 16787-2018 de las trece horas y cuarenta y un minutos del cinco de octubre. 


\section{DERECHO ELECTORAL}

Tribunal Supremo de Elecciones de la República de Costa Rica. (2015). Voto 1337-E1-2015 de las once horas con treinta minutos del once de marzo.

Tribunal Supremo de Elecciones de la República de Costa Rica. (2019). Voto 8764-E3-2019 de las once horas con treinta minutos del doce de diciembre.

\section{ACTAS}

Tribunal Supremo de Elecciones de la República de Costa Rica. (2018). Acta 492018 de nueve horas con cuarenta y cinco minutos del catorce de mayo.

\section{SITIOS WEB}

Alvarado, J. (2017). Por primera vez, una mujer trans es candidata a diputada. Recuperado de https://www.crhoy.com/nacionales/por-primera-vez-una-mujertrans-es-candidata-a-diputada/. 